\title{
A Sociologia da Educação em Portugal. Do conhecimento das realidades a discursos paralelos
}

\author{
António Teodoro²
}

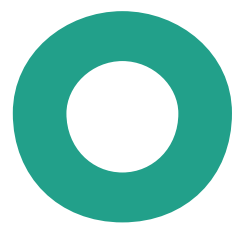

sociólogo britânico Anthony Giddens lembrava que as teorias produzidas em Ciências Sociais não são somente quadros de referência, mas constituem também "intervenções morais na vida da sociedade, cujas condições de existência procuram clarificar" (Giddens, 1996, p.8). É, nesta perspetiva, que se apresenta este texto, elaborado mais como um depoimento de alguém que viveu muitos dos caminhos referidos, seja primeiro como ator político seja depois como cientista social e professor universitário, do que propriamente um artigo sobre o estado da arte no campo da Sociologia da Educação em Portugal. Outros já o fizeram num passado relativamente recente, nomeadamente numa das revistas que publica o presente depoimento (ver Afonso, 2009).

Em Portugal, foi a Revolução dos Cravos, em 25 de abril de 1974, que permitiu a afirmação da Sociologia da Educação como disciplina com lugar na universidade e nos meios científicos. Embora se possam assinalar trabalhos de natureza sociológica em períodos anteriores, tanto na I República (1910-1926) como na década de 1960 e no início da de 1970 (ver Stoer, 1992), a afirmação como disciplina fez-se após a conquista da Liberdade, em estreita ligação com os campos da formação de professores e da ação transformadora das estruturas educativas herdadas de uma Ditadura de 48 anos. Uma ideia-chave presidiu a esse processo, muito semelhante aliás ao da História da Educação: o conhecimento das realidades portuguesas.

Do período anterior à Revolução de Abril de 1974 importa sublinhar duas linhas distintas de desenvolvimento. Uma, situada a nível da administração e da decisão política, sobretudo ligada às correntes tecnocráticas defensoras de uma maior abertura do regime ditatorial, estimulados a partir do exterior, primacialmente da OECE/OCDE (ver Teodoro, 2019), centrou-se nos estudos de planeamento educativo e de formação de mão-de-obra, enquanto elementos determinantes do crescimento económico. Outra, sem responsabilidades político-administrativas e nas margens da Universidade de então, assumiu outras linhas de pesquisa sobre a realidade educativa portuguesa, e que, depois da Revolução, marcaram decisivamente a afirmação da Sociologia da Educação em Portugal. Duas instituições desempenharam um papel de relevo nesta segunda linha: o Centro de Investigação Pedagógica (CIP) da Fundação Calouste Gulbenkian e o Gabinete de Investigações Sociais (GIS), antecessor do atual Instituto de Ciências Sociais (ICS), laboratório de I\&D integrado na Universidade de Lisboa.

A Revolução de Abril permitiu condições de liberdade de criação que colocaram o conhecimento das realidades portuguesas, no campo da educação como em praticamente todos os campos sociais, no centro

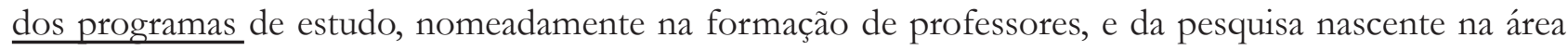


das Ciências da Educação. Verificou-se então o que designei por "sociologização e historicização dos estudos educativos" (Teodoro, 2001, p. 32), em geral motivados pela entrada de pedagogos e políticos nas áreas da Sociologia e da História, bem como de um acréscimo de interesse por parte de sociólogos e de historiadores pelas problemáticas do campo educativo. Essa dupla origem ainda hoje está presente e tem expressão nas duas sociedades científicas que assumem a sociologia da educação como seu campo de representação: a Sociedade Portuguesa de Ciências da Educação, constituída em 1990, e a Associação Portuguesa de Sociologia, fundada em 1985 e que em 2008-09 constituiu uma seção temática de Sociologia da Educação.

Deve-se a Almerindo J. Afonso a sistemática preocupação com o conhecimento da evolução da Sociologia da Educação em Portugal (Afonso, 2005, 2009), embora, todos o lamentamos, o seu último trabalho tenha já mais de uma década. Nesses dois balanços da produção científica portuguesa, Almerindo Afonso apresenta as problemáticas que dominaram desde a constituição do campo até quase ao final da década de 2000. Na listagem apresentada dos temas inicialmente privilegiados, figuram "o sindicalismo e o profissionalismo docentes, os problemas relacionados com a interação nos contextos pedagógicos (como a sala de aula), as análises relativas ao (in)sucesso e ao currículo escolares, as desigualdades sociais e educacionais, a democratização da educação escolar e, em geral, os problemas relativos à nascente escola de massas e à sua complexificação crescente (enquanto escola aberta a todos os grupos e classes sociais)" (Afonso, 2009, p. 67).

Numa interpretação meramente pessoal, após estes balanços de Almerindo Afonso, assistiu-se a um cruzamento de problemáticas e de interesses da Sociologia da Educação com outras áreas de fronteira, nomeadamente os estudos curriculares, a Educação Comparada (e todos os temas associados à globalização/ões), os estudos inter-multiculturais, ou a administração educacional e a regulação da educação. Isso pode ter originado uma perceção de menor atividade e de presença do campo da Sociologia nos estudos educacionais em Portugal.

Mas, a característica mais marcante dos tempos presentes talvez se situe no que tenho designado por discursos paralelos. Simplificadamente, o campo da Educação está atravessado por discursos de vários tipos: o discurso político e mediático, o discurso dos professores e das escolas, e o discurso académico e da produção científica. Estes discursos apresentam, em geral, agendas e temáticas que poucas vezes se intersetam e se fertilizam, com evidentes prejuízos para a qualidade da decisão política, para a presença de uma opinião pública informada, para a mudança dos processos e práticas docentes e também para o conhecimento científico e para o reconhecimento da sua relevância social.

Fazer convergir essas agendas, nomeadamente as que tomam a educação (e a escola pública) como um projeto de ação pela justiça social (e cognitiva), parece-me ser um bom desafio a assumir nos tempos mais próximos por todos aqueles que se posicionam no campo da Sociologia (da Educação).

\section{Referências bibliográficas}

Afonso, A. J. (2009): "Contributos recentes para a sociologia da educação em Portugal: objectos, quadros teóricos e metodologias (2004-2009)". Revista de la Asociación de Sociología de la Educación (RASE), 2 (3), 66-81.

Afonso, A. J. (2005): “A Sociologia da Educação em Portugal. Elementos para a configuração do 'estado da arte" en António Teodoro y Carlos Alberto Torres (Orgs). Educação Crítica \& Utopia. Perspectivas para o século XXI. São Paulo: Cortez Editora. 
Giddens, A. (1996). Novas regras do método sociológico. Uma crítica positiva às sociologias interpretativas (2a ed.). Lisboa: Gradiva. Ed.

Stoer, S. R. (1992): "Notas sobre o desenvolvimento da sociologia da educação em Portugal” en A. J. Esteves y S. Stoer (Eds). A Sociologia na Escola, Professores, Educação e Desenvolvimento. Porto: Afrontamento.

Teodoro, A. (2019). The end of Isolationism: Examining the OECD Influence in Portuguese Education Policies, 1955-1974. Paedagogica Historica. DOI: https://doi.org/10.1080/00309230.2019.1606022.

Teodoro, A. (2001). A Construção Política da Educação. Estado, mudança social e políticas educativas no Portugal contemporâneo. Porto: Afrontamento.

\section{Nota biográfica}

António Teodoro es Professor de Sociologia da Educação e Educação Comparada. Diretor do Centro de Estudos Interdisciplinares em Educação e Desenvolvimento (CeiED), Universidade Lusófona, Lisboa. 